\title{
52 year Male with Haemophila-A; Presented with Scrotal Haematoma: Managed in Resource Constraint Settings - A Case Report
}

\author{
Alam SI ${ }^{1}$, Rahman MM², Rayhan F, ${ }^{3}$ Hasan ASMFU ${ }^{4}$
}

Conflict of Interest: None Received: 08-07-2018

Accepted: $11-09-2018$

www.banglajol.info/index.php/JSSMC

Key Words: Haemophilia A, Scrotal haematoma, factor VIII, Fresh Frozen Plasma

\begin{abstract}
:
Haemophilia $A$ is an X linked disorder characterized by bleeding manifestations due to deficiency offactor VIII. Administration offactor VIII is the mainstay of treatment in case of bleeding which is very costly. That's why fresh frozen plasma is a very good alternative in the management of mild to moderate bleeding. Here we present a case of 50 years old male presented to us with traumatic scrotal haematoma who was newly diagnosed with Haemophilia A. As the patient was unable to bear the cost of factor VIII, we managed the patient by transfusing fresh frozen plasma. After raising his activity of factor VIII up to $30 \%$ which was adequate for soft tissue trauma, surgical exploration of scrotum was done. Both the testes were found viable. Evacuation of clot was done followed by secondary closure of the wound
\end{abstract}

[J Shaheed Suhrawardy Med Coll 2018; 10(2): 118-121] DOI: https://doi.org/10.3329/jssmc.v10i2.41173

\section{Introduction:}

Haemophilia is an X-linked recessive disorder characterized by bleeding manifestations and coagulation abnormalities. The disorder affects approximately 1 in 10,000 male births worldwide; $80 \%$ of cases are of factor VIII deficiency or Haemophilia A and $20 \%$ are factor IX deficiency or Hemophilia B. ${ }^{1}$ Haemophilia-A is more common form of the disease and is associated with deûciency of factor VIII. Factor VIII is an essential blood-clotting factor which takes part in intrinsic coagulation pathway by interacting with factor IXa in the presence of $\mathrm{Ca}^{2+}$ and converts factor $\mathrm{X}$ to the activated form $\mathrm{Xa}^{2}$

Because of it's mode of inheritance, men are mostly affected by Haemiphila A while females remain as carriers. ${ }^{3} \mathrm{~A}$ family history is frequently present in haemophilic patients. The disease is characterized by bleeding into the joints (hemarthrosis), skeletal muscle, soft tissues, and enclosed spaces such as the intracranium and retroperitoneum,

1. Dr. Shoaeb Imtiaz Alam, Honorary Medical Officer, Deparment of Surgery, Shaheed Suhrawardy Medical College \& Hospital, Dhaka

2. Professor Dr. Md. Mustafizur Rahman, Professor, Deparment of Surgery, Shaheed Suhrawardy Medical College \& Hospital, Dhaka

3. Dr. Ferdoush Rayhan, Medical Officer, Department of Surgery, Shaheed Suhrawardy Medical College \& Hospital, Dhaka

4. Dr. A.S.M. Farhad-U1-Hasan, Resident Surgeon (Casualty), Shaheed Suhrawardy Medical College \& Hospital, Dhaka

Correspondence to: Dr. Shoaeb Imtiaj Alam, Honorary Medical Officer, Deparment of Surgery, Shaheed Suhrawardy Medical College \& Hospital, Dhaka which can be fatal. The factor VIII level correlates directly with bleeding type where in patients with severe disease $(<1 \%)$ present with spontaneous bleeds, those with moderate disease (1-5\%) bleed with minor trauma and rarely spontaneously, and those with mild disease (6-30\%) bleed only secondary to trauma or invasive procedures. 4

The standard treatment of haemophilia is administration of factor VIII according to body weight and severity of the disease. Desmopressin may be used in those with mild haemophilia A. ${ }^{4}$ Tranexamic acid or aminocaproic acid may be given along with clotting factors to prevent breakdown of clots. In those with severe hemophilia A already receiving factor VIII, emicizumab may provide some benefit. ${ }^{4}$ But all these treatment modalities are very costly. But in a resource-limited country like Bangladesh, it is usually not feasible for the patients who are suffering from life threatening bleeding due to haemophilia A.

In these resource constraints settings fresh frozen plasma (FFP) is a very good alternative to factor VIII. Fresh frozen plasma (FFP) is a blood product made from the liquid portion of whole blood containing plasma proteins and clotting factors. FFP is made by centrifugation of whole blood or apheresis device followed by freezing and preservation. ${ }^{5}$ It is frozen solid at $-18{ }^{\circ} \mathrm{C}\left(0^{\circ} \mathrm{F}\right)$ or colder within eight hours of collection. ${ }^{5}$ One bag of FFP contains about 220-250 $\mathrm{ml}$ of plasma having about 80-200 UI of factor VIII. ${ }^{6}$ Though there is chance of fluid overload but by meticulous administration of FFP it can be minimized. 
Here we present a case where a 50 years old man from a poor socio-economic status presented to us with traumatic scrotal haematoma having Haemophilia A and managed by transfusion of fresh frozen plasma.

\section{Case summary:}

A 50 year old male was presented to the surgery department of Shaheed Sohrawardy Medical College and Hospital with the complaints of painful swelling of scrotum following trauma one day back. On query, he gave a history that his elder brother died due to lack of arrest of bleeding following tooth extraction. His younger brother also died following circumcision due to lack of arrest of bleeding. His younger sister was in good health. His other family members were not suffering such type of illness especially in his maternal family. He also gave history of experiencing easy bruisability and joint swelling following minor trauma since his childhood. On examination his vitals were within normal limit. On local examination his scrotum was swollen and tender. There was penile edema associated with subcutaneous haematoma in the both inguinal region which was extending towards the lower abdomen. His systemic examination revealed normal findings. His complete blood count including platelet count, serum creatinine, liver function tests, chest X-ray and ECG were normal. His ultrasonography report revealed suspected bilateral torsion of testes with decreased blood flow on both testes (Fig-1). His bleeding time, clotting time and prothrombin time were within normal range. But his activated partial thromboplastin time (APTT) was 80 seconds which was prolonged. So he was advised for

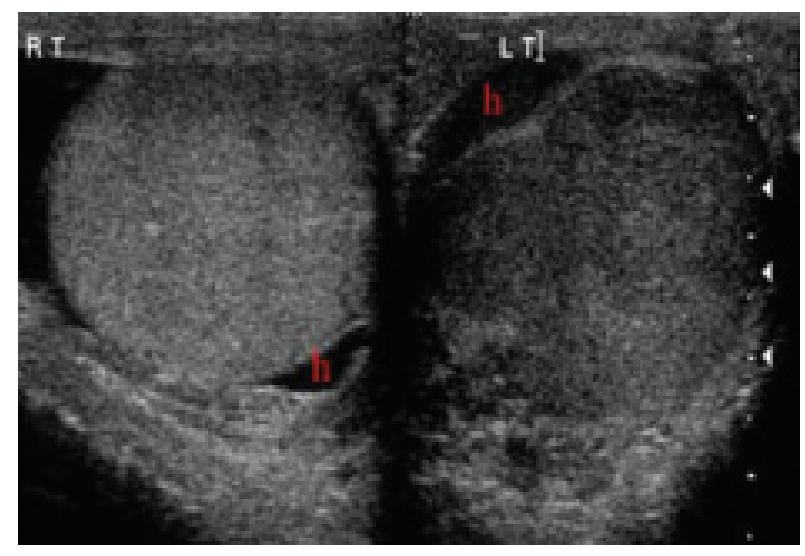

Fig-1: USG shows suspected bilateral torsion of testis.

factor VIII and IX assay which showed normal activity of factor XI but factor VIII activity was only $15 \%$. So our final diagnosis was scrotal haematoma with suspected bilateral torsion testis with Haemophilia A. As his scrotal swelling was not resolving and USG showed suspected bilateral torsion testes we decided to go for surgical exploration of scrotum. But as the patient was unable to purchase factor VIII, we decided to manage the patient by transfusing fresh frozen plasma (FFP) after taking consultation from transfusion medicine department. Since there was trauma to the soft tissue, we decided to raise the factor VIII activity up to $30 \%$. So he required about $525 \mathrm{IU}$ of factor VIII per day to maintain his factor VIII activity up to $30 \%$ as his body weight was $70 \mathrm{~kg}$ (Requirement of factor VIII = (Desired factor VIII activity- Current activity) $\times$ body weight $/ 2$ ). In order to achieve that he was advised to transfuse six units of FFP per day considering each bag of FFP contains at least 80 IU of factor VIII. So FFP was transfused with administration Inj. Frusemide after transfusion of every third bag to avoid fluid overload. Tranexamic acid was also administered to the patient. Then surgical exploration was done and huge amount of clotted blood was evacuated from scrotum. Both the testes were found viable and the wound was kept open as the tissues were edematous and friable. (Fig-2) Patient was transfused FFP regularly as per previous schedule in the postoperative period as half-life of factor VIII is very short (812 hours).After seven days his wound became healthy, penile edema and subcuteous haematoma were resolved.

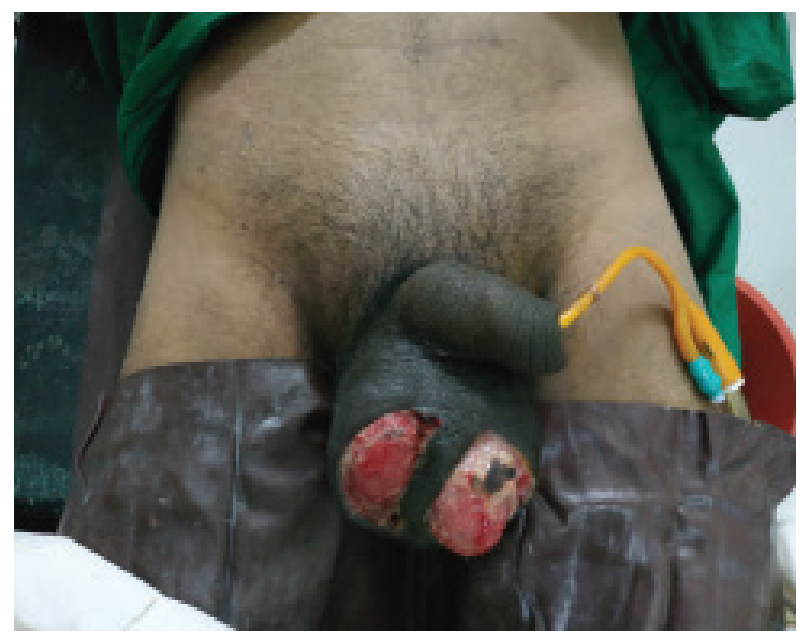

Fig-2 shows viability of both testis and resolution of haematoma after administering FFP (Photo was taken with the kind permission of the patient)

So secondary closure was done (Fig-3) and stitches were removed after 14 days. He was discharged on $15^{\text {th }}$ postoperative day following the secondary closure and referred to transfusion medicine department for further management. 


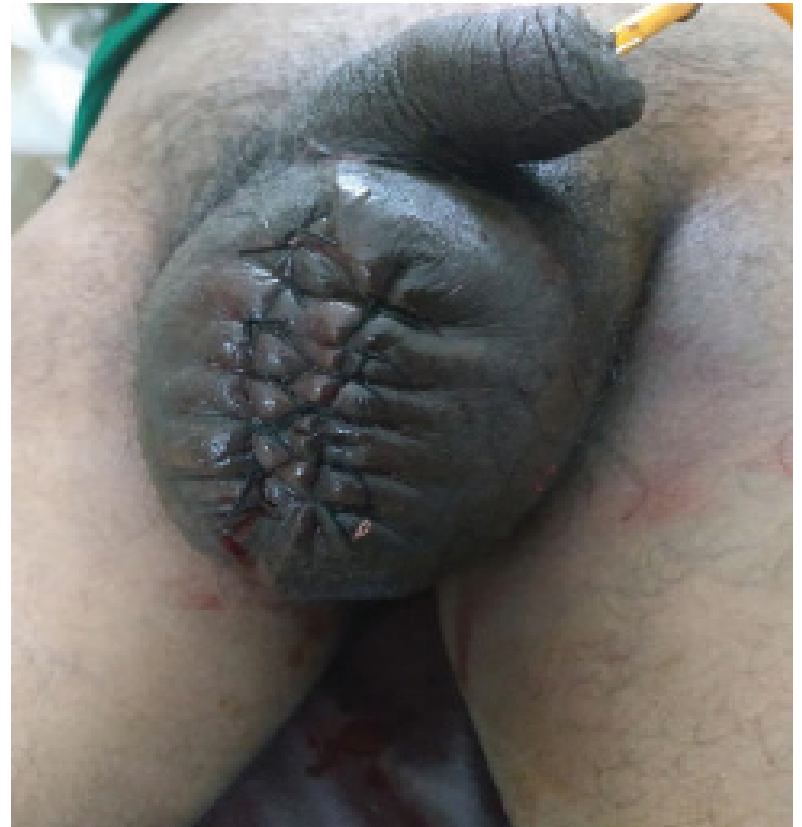

Fig- 3: Picture of scrotum after secondary closure

\section{Discussion:}

Hemophilia is an inherited bleeding disorder in which the blood does not clot properly. This can lead to spontaneous bleeding as well as prolonged bleeding following injuries or surgery. Haemophilia A is caused by various mutations in the factor VIII gene, which is located on the Xchromosome. ${ }^{7}$ Since this disorder is transmitted as an $\mathrm{X}$ linked recessive trait, it occurs mainly in males. Current treatment includes replacement therapy with recombinant factor VIII concentrates either "on demand" for acute bleeding or prophylactically to prevent bleeding. ${ }^{8}$ But the cost of these treatment modalities are very high which is very difficult to afford especially for the patients belonging to poor socioeconomic status. In our country, the cost of commercially available $500 \mathrm{IU}$ of factor VII ranges from 3000-4000 taka. A patient weighing $50 \mathrm{~kg}$ with mild Haemophilia A will require about 3500 IU of factor VII to raise his factor VII activity up to $100 \%$. Then the patient has to spend taka $20,000-30,000$ per day. So cost is a significant barrier for the treatment of Haemophilia A. In these situations fresh frozen plasma (FFP) is a very good alternative to factor VIII.

There has been many reports of using FFP for correction of factor VIII activity especially in developing countries where patients are unable to bear the costing of commercially prepared factor VIII. ${ }^{9}$

During acute bleeding, factor VIII is given to raise activity based on the severity of the hemorrhage. In a lifethreatening hemorrhage, factor is initially infused to a target activity of $80 \%$ to $100 \%$, whereas in mild to moderate bleeding the goal is factor activity of $30 \%$ to $50 \% .{ }^{10}$ As our patient presented to us with scrotal injury which is a soft tissue trauma we decided to raise the level of factor VIII up to $30 \%$.

Testicular torsion is a surgical emergency that requires immediate intervention to restore the flow of blood to the testicle. With prompt diagnosis and treatment the testicle can often be saved. Trauma is an important causative agent of torsion testis. If untreated it may lead to gangrene, reperfusion injury and infertility. ${ }^{11}$ Though our patient was in great risk of bleeding as he was diagnosed with hemophilia, we have to go for surgical exploration of scrotum after optimizing the patient by transfusing FFP as USG revealed a suspicion of torsion testis associated with expanding haematoma.

Surgery represents a major bleeding risk for patients with hemophilia. Before major surgery factor activity is raised to normal levels. Factor VIII is administered by repeated bolus injection or continuous intraoperative infusion, and levels are maintained at a normal level for 1 to 2 weeks afterward to promote wound healing. ${ }^{12}$ Aminocaproic acid and tranexamic acid are lysine analogues that act as competitive inhibitors of plasminogen. These can be used for clot stabilization after surgical interventions. In our patient we also did the same but we managed to raise the factor VIII level by transfusing FFP in combination with tranexamic acid which was cost effective.

Fluid overload is the major limitations for FFP transfusion. ${ }^{13}$ That's why we were very cautious regarding the fluid management of the patient. Regular intake and output chart was maintained and frusemide was administered intravenously to prevent fluid overload.

\section{Conclusion:}

Haematoma formation from trauma is a common manifestations of the patients having haemophilia. Though administration of factor VIII is recommended, it is not possible to bear the cost of factor VIII in developing countries. In a resource-constrained situations, management of bleeding in Haemophilia patients should be promptly started with alternative therapy like fresh frozen plasma in order to decrease the morbidity and mortality of the patients.

\section{References:}

1. Soensen B, Benson G M, Bladen M. Management of muscle haematomas in patients with severe haemophiliainan evidence-poor world. Haemophilia 2012; 18:598-606.

2. Bolton-Maggs PH, Pasi KJ. Hemophilias $\mathrm{A}$ and B. Lancet. 2003; 361:1801-1809. doi: 10.1016/S01406736(03)13405-8 
3. Mannucci PM. Hemophilia and related bleeding disorders: a story of dismay and success. Hematology Am Soc Hematol Educ Program. 2002; 1:1-9.

4. White GC, McMillan CW, Kingdon HS, Shoemaker CB. Use of recombinant antihemophilic factor in the treatment of two patients with classic hemophilia. N Engl J Med. 1989; 320:166-170.

5. Nascimento B, Callum J, Rubenfeld G, et al. Clinical review: fresh frozen plasma in massive bleedings - more questions than answers. Crit Care 2010; 14:202.

6. Chng WJ, Tan MK, Kuperan P. An audit of fresh frozen plasma usage in an acute general hospital in Singapore. Singapore Med J. 2003;44:574-8

7. Ahlberg A. Haemophilia in Sweden. VII. Incidence, treatment and prophylaxis of arthropathy and other musculoskeletal manifestations of hemophilia A and B. Acta Orthop Scand Suppl. 1965; 77:3-132.
8. Nilsson IM, Berntorp E, Löfqvist T, Pettersson H. Twentyfive years experience of prophylactic treatment in severe haemophilia A and B. J Intern Med. 1992;232(1):25-32.

9. Rosendaal G. Pathogenesis of hemophilic arthropathy. Haemophilia. 2006; 12:117-121.

10. Plug I, van der Bom JG, Peters M, et al. Thirty years of hemophilia treatment in the Netherlands, 19722001. Blood. 2004; 104(12):3494-3500.

11. Makela E, Lahdes-Vasama T, Rajakorpi H, Wikström S. A 19-year review of paediatric patients with acute scrotum. Scand J Surg. 2007; 96:62-66.

12. Franchini M, Coppola A, Molinari AC, et al. Forum on the role of recombinant factor VIII in children with severe haemophilia A. Haemophilia. 2009;15(2):578-586

13. Holland LL, Brooks JP. Toward rational fresh frozen plasma transfusion: the effect of plasma transfusion on coagulation test results. Am J Clin Pathol 2006; 126: 133-139. 